\title{
Mechanisms of Microbially Influenced Corrosion
}

\author{
Z. Lewandowski (四) and H. Beyenal
}

\begin{abstract}
The chapter demonstrates that biofilms can influence the corrosion of metals (1) by consuming oxygen, the cathodic reactant; (2) by increasing the mass transport of the corrosion reactants and products, therefore changing the kinetics of the corrosion process; (3) by generating corrosive substances; and (4) by generating substances that serve as auxiliary cathodic reactants. These interactions do not exhaust the possible mechanisms by which biofilm microorganisms may affect the corrosion of metals; rather, they represent those few instances in which we understand the microbial reactions and their effect on the electrochemical reactions characteristic of corrosion. In addition, we can use electrochemical and chemical measurements to detect one or more products of these reactions. An important aspect of quantifying mechanisms of microbially influenced corrosion is to demonstrate how the microbial reactions interfere with the corrosion processes and, based on this, identify products of these reactions on the surfaces of corroding metals using appropriate analytical techniques. The existence of these products, associated with the increasing corrosion rate, is used as evidence that the specific mechanism of microbially influenced corrosion is active. There is no universal mechanism of MIC. Instead, many mechanisms exist and some of them have been described and quantified better than other. Therefore, it does not seem reasonable to search for universal mechanisms, but it does seem reasonable to search for evidence of specific, well-defined microbial involvement in corrosion of metals.
\end{abstract}

\section{Recent Views on Microbially Influenced Corrosion}

When it is suspected that a material failure was caused by microbial corrosion, it is reasonable to ask: "How do we know that the corrosion process was influenced by microorganisms?" To address this question, many research groups

Z. Lewandowski

Department of Civil Engineering and Center for Biofilm Engineering, Montana State University, Room 310, EPS Building, Bozeman, MT 59717, USA e-mail: ZL@erc.montana.edu 
have attempted to find a fingerprint of microbially influenced corrosion(MIC), i.e., specific characteristics distinguishing microbially stimulated corrosion from ordinary galvanic corrosion (Beech et al. 2005; Javaherdashti 1999; Lee et al. 1995; Little et al. 2000, 2007; Mansfeld and Little 1991; Videla and Herrera 2005; Wang et al. 2006). Despite significant research effort, no such fingerprint characteristic of MIC has yet been found, and there are good reasons to believe that a universal mechanism of microbially stimulated corrosion does not exist (Beech et al. 2005; Flemming and Wingender 2001; Miyanaga et al. 2007; Starosvetsky et al. 2007). Instead of a universal mechanism, several mechanisms by which microorganisms affect the rates of corrosion have been described, and the diversity of these mechanisms is such that it is difficult to expect that a single unified concept can be conceived to bring them all together. From what we now understand, and what has been demonstrated by numerous researchers, accelerated corrosion of metals in the presence of microorganisms stems from microbial modifications to the chemical environment near metal surfaces (Beech et al. 2005; Geiser et al. 2002; Lee and Newman 2003; Lewandowski et al. 1997). Such modifications depend, of course, on the properties of the corroding metal and on the microbial community structure of the biofilm deposited on the metal surface (Beech and Sunner 2004; Dickinson et al. 1996b; Flemming 1995; Olesen et al. 2000b, 2001). The conclusion that there are many mechanisms of MIC, rather than a single one, is generally accepted in the literature and can be exemplified by the paper by Starosvetsky et al. (2007), who concluded that to uncover MIC in technological equipment failures requires an individual approach to each case, and that an assessment of the destructive role of the microorganisms present in the surrounding medium is possible only by analyzing and simulating the corrosion parameters found in the field (Dickinson and Lewandowski 1998). Quite succinctly, Beech et al. (2005) describe MIC as a consequence of coupled biological and abiotic electron-transfer reactions, i.e., redox reactions of metals enabled by microbial ecology. Hamilton (2003) attempted to generate a unified concept of MIC and has found common features in only some of the possible mechanisms. It is unlikely that a unified concept of MIC can be generated at all.

MIC is caused by microbial communities attached to surfaces, known as biofilms. A biofilm is composed of four compartments: (1) the surface to which the microorganisms are attached, (2) the biofilm (the microorganisms and the matrix), (3) the solution of nutrients, and (4) the gas phase (Lewandowski and Beyenal 2007). Each compartment consists of several components, and the number of components may vary depending on the type of study. For example, in some MIC studies it is convenient to distinguish four components of the surface: (1) the bulk metal, (2) the passive layers, (3) the biomineralized deposits on the surface, and (4) the corrosion products. Microorganisms can modify each of these components in a way that enhances corrosion of the metal surface. In addition, components of the other compartments of the biofilm can be modified in ways that affect the corrosion reactions as well. Modifications in the solution compartment may include the chemical composition, hydrodynamics and mass transfer rates near the metal surface; modifications in the biofilm compartment may include the microbial
community structure and the composition of the extracellular polymeric substances (EPS). Each of these modifications may be complex in itself, and each may affect the corrosion reactions in many ways. The complexity and the multitude of the possible interactions among microorganisms, their metabolic reactions, the corrosion reactions and the metal, such as those shown by Coetser and Cloete (2005), are the reasons why it is unlikely that a unifying concept of MIC can be developed (Coetser and Cloete 2005).

When biofilms accumulate on metal surfaces, reactants and products of microbial metabolic reactions occurring in the space occupied by the biofilm affect the solution chemistry and the surface chemistry, and both types of modification may interfere with the electrochemical processes naturally occurring at the interface between the metal and its environment. The reactants and products of electrochemical reactions occurring at a metal surface interact with the reactants and products of microbial metabolic processes occurring in biofilms in a complex way. Some of these interactions accelerate corrosion, and some may inhibit corrosion. The interactions that accelerate corrosion, and are characteristic enough, are called mechanisms of MIC, and much of this text is devoted to quantifying the mechanisms that we now understand. To approach the task of quantifying these interactions in an organized manner, we will start by describing the reactions characterized as galvanic corrosion and then assess the effects of various metabolic reactions on these reactions. Corrosion science has developed a succinct system of quantifying various forms of corrosion, and we will use this system to quantify the effects of microbial metabolic reactions on corrosion by referring to the principles of the chemistry and electrochemistry of metals immersed in water solutions. Traditionally, the mechanisms of corrosion are quantified using thermodynamics and kinetics, and we will follow this tradition here.

The term corrosion can be defined in various ways, and there are many forms of corrosion and many materials that can corrode - both metallic and nonmetallic. Among the well-known processes of nonmetallic corrosion is the corrosion of stone and its effect on ancient artifacts. Here, we restrict the meaning of corrosion and define it as the anodic dissolution of metals. Among the many anodic reactions that may occur at the surface of a metal, the one in which the metal itself is the reactant subjected to oxidation is singled out and termed corrosion. Noble metals, such as platinum and gold, do not undergo an oxidation reaction and serve only to facilitate charge transfer between external redox species. In contrast, active metals such as iron are oxidized and this process contributes to the net anodic reaction rate, which is typically the dominant anodic process for freely corroding metals. On corroding metals, anodic reactions are coupled with cathodic reactions (reduction). In aerated water solutions, the dominant cathodic reaction is the reduction of dissolved oxygen, while in anaerobic solutions, the reduction of protons is the dominant cathodic reaction; this is typically represented as the reduction of water.

Equations (1)-(6) show the relevant half reactions, followed by the corresponding net reactions, for the corrosion of ironin aqueous media (Lewandowski et al. 1997). 
Anaerobic

$$
\begin{aligned}
& \mathrm{Fe} \rightarrow \mathrm{Fe}^{2+}+2 \mathrm{e}^{-} \text {anodic } \\
& 2 \mathrm{H}_{2} \mathrm{O}+2 \mathrm{e}^{-} \rightarrow \mathrm{H}_{2}+2 \mathrm{OH}^{-} \text {cathodic } \\
& 2 \mathrm{H}_{2} \mathrm{O}+\mathrm{Fe} \rightarrow \mathrm{Fe}(\mathrm{OH})_{2}+\mathrm{H}_{2} \text { net }
\end{aligned}
$$

Aerobic

In aerobic solutions, the basic anodic reaction is of course the same as the one described by (1) - dissolution of iron - but the products of the reaction, ferric ions, are hydrolyzed and further oxidized by the available oxygen, and all these reactions are summarized as follows:

$$
\begin{aligned}
& 4 \mathrm{OH}^{-}+4 \mathrm{Fe}(\mathrm{OH})_{2} \rightarrow 4 \mathrm{Fe}(\mathrm{OH})_{3}+4 \mathrm{e}^{-} \text {anodic } \\
& \mathrm{O}_{2}+2 \mathrm{H}_{2} \mathrm{O}+4 \mathrm{e}^{-} \rightarrow 4 \mathrm{OH}^{-} \text {cathodic } \\
& 4 \mathrm{Fe}(\mathrm{OH})_{2}+\mathrm{O}_{2}+2 \mathrm{H}_{2} \mathrm{O} \rightarrow 4 \mathrm{Fe}(\mathrm{OH})_{3} \text { net }
\end{aligned}
$$

These corrosion reactions can be modified by the metabolic reactions in biofilms in many ways, and we will discuss four possible modifications here:

1. Biofilms create oxygen heterogeneities near a metal surface.

2. Biofilm matrix increases mass transport resistance near a metal surface.

3. Metabolic reactions in biofilms generate corrosive substances, such as acids.

4. Metabolic reactions in biofilms generate substances that serve as cathodic reactants.

These four possible interactions do not exhaust the possible effects of microorganisms on corrosion reactions. The reason we have selected these four interactions is that they have been extensively studied, and so we know more about them than we know about other interactions. Other mechanisms, both accelerating and inhibiting corrosion, are continually proposed and studied. For obvious reasons, using biofilms to inhibit the corrosion of metals stimulates imaginations, and several authors have described such scenarios. For example, Jayaraman et al. (1999) demonstrated axenic aerobic biofilms inhibiting generalized corrosion of copper and aluminum. Similarly, in the work by Zuo et al. (2005), Al 2024 was passive in artificial seawater in the presence of a protective biofilm of Bacillus subtilis WB600. When antibiotics were added to the artificial seawater to kill the bacteria in the biofilm, pitting occurred within a few hours (Zuo et al. 2005). However, as summarized by Little and Ray (2002), most of the experiments on inhibiting corrosion with biofilms were done in laboratories, and when the biofilms were exposed to natural waters they failed to protect the material. Clearly, the laboratory biofilms were different from those deposited in nature. One assumption made in attempting to use biofilms to inhibit corrosion is that biofilm formation is predictable and controllable (Little and Ray 2002). This is not true. Even pure culture biofilms in laboratory are not uniform and their structure changes all the time (Lewandowski et al. 2004).

Corroding metals fall into two categories: active metals - such as iron, and passive metals - such as stainless steels. These two types of materials are affected by different types of corrosion. To demonstrate the possible microbial modifications of the corrosion reactions, we need to specify the reactions characteristic of each type of corrosion affecting these materials.

\section{Corrosion of Active Metals}

\subsection{Thermodynamics of Iron Corrosion}

Using the terminology accepted in electrochemical studies, a metal immersed in water is called an electrode. The potential of an electrode in an aqueous solution depends on the rates of the anodic (oxidation) and cathodic (reduction) reactions occurring at the metal surface. When these rates are at equilibrium, thermodynamics can be used to quantify the electrode potential. When these rates are not at equilibrium, thermodynamics cannot be used to find the electrode potential and it must be found empirically. Corrosion reactions are not at equilibrium, and the potentials of corroding metals cannot be predicted from thermodynamics.

To illustrate the thermodynamic principles of galvanic corrosion, we will select a set of conditions and compute the potentials of the reactions participating in the corrosion of iron. For the anodic reaction,

$$
\mathrm{Fe}^{2+}+2 \mathrm{e}^{-} \rightarrow \mathrm{Fe} \quad E^{0}=-0.44 \mathrm{~V}_{\mathrm{SHE}}
$$

The Nernst equation quantifies the half-cell potential for iron oxidation as

$$
E=E^{0}-\frac{0.059}{n} \log \left[\frac{1}{\left[\mathrm{Fe}^{2+}\right]}\right]
$$

Iron is a solid metal and its activity equals one. Consequently, the potential of the anodic half reaction depends on the concentration of ferrous ions in the solution and is computed as

$$
E=-0.44+(0.059 / 2) \log \left[\mathrm{Fe}^{2+}\right]
$$

Selecting the concentration of ferrous iron, $\left[\mathrm{Fe}^{2+}\right]=10^{-6} \mathrm{M}$, the potential equals $E=-0.62 \mathrm{~V}_{\mathrm{SHE}}$. 
The cathodic reaction- the reduction of oxygen:

$$
\mathrm{O}_{2}+2 \mathrm{H}_{2} \mathrm{O}+4 \mathrm{e}^{-} \rightarrow 4 \mathrm{OH}^{-} \quad E^{0}=+0.401 \mathrm{~V}_{\mathrm{SHE}}
$$

'he Nernst equation quantifies the half-cell potential for oxygen reduction:

$$
E=E^{0}-\frac{0.059}{n} \log \left[\frac{\left[\mathrm{OH}^{-}\right]^{4}}{p \mathrm{O}_{2}}\right]
$$

'he potential of this half reaction depends on the partial pressure of oxygen and on re $\mathrm{pH}$.

$$
E=0.401+0.059 / 4\left[\log \left(\mathrm{pO}_{2}\right)+4(14-\mathrm{pH})\right]
$$

ssuming that $p\left(\mathrm{O}_{2}\right)=0.2$ atm and $\mathrm{pH} 7$, the potential of the cathodic reaction is $=0.804 \mathrm{~V}_{\mathrm{SHE}}$.

If only one of these reactions were occurring on the metal surface, the metal rould assume the respective potential specified for the reaction. For example, if nly the cathodic reaction were taking place, the metal would have the potential $0.804 \mathrm{~V}_{\mathrm{SHE}}$, and if only the anodic reaction were taking place, the metal would ave the potential $-0.62 \mathrm{~V}_{\mathrm{SHE}}$. This can be demonstrated in electrochemical studies there the anode and the cathode can be separated, placed in different half-cells, nd studied in isolation. However, in corrosion, both reactions occur on the same iece of metal and at the same time, and the potential of the metal can have only ne value. As a result, the potential of the corroding metal is somewhere between le potential of the anodic half reaction, $-0.62 \mathrm{~V}_{\mathrm{SHE}}$, and the potential of the athodic half reaction, $+0.804 \mathrm{~V}_{\mathrm{SHE}}$. The exact potential of the corroding metal epends on the kinetics (reaction rates) of the anodic and cathodic reactions, and an be measured empirically and interpreted from the theory of mixed potentials. lere, for the purpose of this simplified argument, it is enough to assume that the otential of the corroding iron is between the potentials of the anodic and cathodic alf reactions, say, in the middle: $E=(-0.62+0.804) / 2=0.092 \mathrm{~V}_{\mathrm{SHE}}$. Setting the otential of the metal between the potential of the anodic and cathodic half reacons has consequences: it sets the position of the equilibrium for each of the parcipating reactions. If the potential were equal to that computed for either of the alf reactions, anodic or cathodic, this half reaction would be at equilibrium. If the otential of the corroding iron is between the potentials computed for the two half zactions, none of these half reactions (1)-(6) are at equilibrium and each of them roceeds in the direction that approaches the equilibrium. To quantify the conseuences of this departure from the equilibrium, we can inspect the Nernst equation escribing potentials of the anodic and cathodic half reactions when the potentials re shifted from their respective equilibrium potentials. If the potential of the cording iron is $0.092 \mathrm{~V}_{\mathrm{SHE}}$, it is higher than the equilibrium potential for the anodic zaction and lower than the equilibrium potential for the cathodic reaction. As a consequence, each reaction will proceed spontaneously toward reaching the equilibrium determined by the potential of the metal, by adjusting the concentrations of the reactants and products to satisfy the equilibrium for the given potential.

The anodic reaction, $\mathrm{Fe}^{2+}+2 \mathrm{e}^{-} \rightarrow \mathrm{Fe}$, must adjust its potential to $+0.092 \mathrm{~V}$

$$
+0.092=-0.44+(0.059 / 2) \log \left[\mathrm{Fe}^{2+}\right]
$$

If separated from the cathodic reaction, this reaction has a potential of $E=-0.62 \mathrm{~V}_{\mathrm{SHE}}$ When connected to the cathodic reaction, this reaction has a new equilibrium potential, $E=+0.092 \mathrm{~V}_{\mathrm{SHE}}$. To reach the new equilibrium potential, the concentration of ferric ions must increase. Consequently, the reaction proceeds to the left, to increase the concentration of ferric ions in the solution. Iron dissolves in this reaction.

The cathodic reaction, $\mathrm{O}_{2}+2 \mathrm{H}_{2} \mathrm{O}+4 \mathrm{e}^{-} \rightarrow 4 \mathrm{OH}^{-}$must adjust its potential to $+0.0092 \mathrm{~V}$ as well:

$$
+0.092=0.401+0.059 / 4\left[\log \left(p \mathrm{O}_{2}\right)+4(14-\mathrm{pH})\right]
$$
If separated from the anodic reaction, this reaction has a potential of $E=+0.804 \mathrm{~V}_{\mathrm{SHE}}$
When connected to the anodic reaction, this reaction has a new equilibrium potential, $E=+0.092 \mathrm{~V}_{\mathrm{SHE}}$. To reach this new equilibrium potential, the reaction proceeds to the right, to decrease the partial pressure of oxygen. Oxygen is consumed in this reaction.

As a result of setting the metal potential between the equilibrium potentials for the anodic and cathodic half reactions, the anodic reaction spontaneously proceeds toward dissolution of the iron and the cathodic reaction spontaneously proceeds toward reduction of the oxygen. Both reactions proceed until one of the reactants is exhausted or until they both adjust the concentrations of their respective reactants to reach the new equilibrium at $0.092 \mathrm{~V}_{\mathrm{SHE}}$. The thermodynamics of the corrosion processes explains why these processes occur but of course cannot predict the anodic or cathodic reaction rates. Kinetic computations are needed to refine what was said in the section dedicated to thermodynamic considerations.

\subsection{Kinetics of Iron Corrosion}

As discussed in the previous section, the anodic and cathodic processes occurring on metal surfaces correspond to different half reactions, and the electrode potential is used to predict the directions in which these reactions will proceed. Typically, the corrosion reactions occurring on the surfaces of corroding metals are the dominant redox reactions. However, the metal can always serve as a source or sink for electrons satisfying the dissolved redox couples in the solution, and more than one redox reaction can occur on the surface. There is a possibility that more than one reaction is occurring on the metal surface at a time and that each of the reactions uses the electrode as a source or a sink for the electrons needed to reach its own equilibrium 
potential. The term "mixed potential" is used to describe this condition, to distinguish it from the reduction-oxidation potential in which the anodic and cathodic reactions are simply the forward and reverse parts of a single reaction. The mixed potential in which the anodic reaction is metal oxidation is termed the corrosion potential, $E_{\text {corr }}$.

Let us use, as an example, the reaction described by (1) as the electrode reaction an iron electrode immersed in a solution of ferrous ions. At equilibrium, the exchange of electrical charges between the electronic conductor - the electrode - and the ionic conductors - ferrous ions in the solution - is composed of two streams of electrical charges moving in opposite directions, to and from the electrode. In the forward reaction, ferrous ions from the metal lattice are dissolved in water. In the reverse reaction, ferrous ions are reduced and deposited on the surface of the electrode as iron atoms. At equilibrium, the rates of the charge transfers across the interface are equal to each other, and there is no net current flow across the interface; the potential at equilibrium is named $E_{\text {eq }}$, and the current flowing in opposite directions, named the exchange current, is usually quantified as the exchange current density, $i_{0}$. Once the electrode potential departs from equilibrium and an overpotential is applied, the electrode reaction is no longer at equilibrium and a net current flows in one direction. The direction in which this net current flows is determined by the sign of the applied overpotential: a negative sign is equivalent to cathodic polarization and a positive sign is equivalent to anodic polarization. This can be summarized as follows:

From the definition of overpotential, $E=E_{\text {eq }}+\eta$, we assign cathodic polarization:

$$
\eta=\left(E-E_{\text {eq }}\right)<0
$$

$$
\text { Anodic polarization: } \eta=\left(E-E_{\mathrm{eq}}\right)>0
$$

The magnitude of the net current is determined by the extent of the overpotential $(\eta)$ and by the intrinsic properties of the system, summarized by the exchange current density, $i_{0}$. At this condition, even though the currents in the two directions are equal, in various systems these currents may have different magnitudes, depending on the material of the electrode and the type of the electrode reaction. Polarizing the electrode, i.e., applying an overpotential, favors the flow of electric charges in one direction and inhibits the flow in the opposite direction: positive polarization amplifies the anodic current and negative polarization amplifies the cathodic current. The following equation, somewhat simplified, is known as the Butler-Volmer equation, and it quantifies the net current, equal to the difference in rate of charge transfer between the anodic and cathodic directions:

$$
i=i_{\mathrm{c}}-i_{\mathrm{a}}=i_{0}\left[\exp \left(\frac{-\alpha F \eta}{R T}\right)-\exp \left(\frac{\alpha F \eta}{R T}\right)\right]
$$

where $\alpha$ is the symmetry coefficient and is assumed to be equal to 0.5 , and the remaining symbols $-\mathrm{F}, \mathrm{R}$, and $\mathrm{T}$ - have their usual meanings. When applied potential $\eta$ is negative (cathodic polarization), the first exponential expression in the ButlerVolmer equation becomes positive and the second becomes negative. As a result, the second exponential expression is, for practical reasons, negligibly small when compared with the first exponential expression; i.e., the anodic current is negligibly small when compared with the cathodic current. The opposite is true when the overpotential has a positive sign (anodic polarization). Figure 1 shows the relation between the applied potential and the current: the potentiodynamic polarization curve.

\subsection{Microbially Stimulated Modifications of the Corrosion of Iron and Active Metals}

In corrosion, the anodic and cathodic reactions are not at equilibrium but they are related to each other by two requirements:

1. The two reactions progress on the same piece of metal, and so they must have the same potential.

2. Electrons extracted in the anodic reactions are used in the cathodic reactions; therefore, the anodic and the cathodic currents must be equal.

These two requirements combined are used to quantify the thermodynamics and kinetics of the corrosion process - the corrosion potential and the corrosion current, as shown in Fig. 2.

The reactants and products of microbial metabolism in biofilms may interact with the corrosion reactions, and these interactions may affect the thermodynamics of the process, e.g., by introducing an additional cathodic reactant and thus altering the position

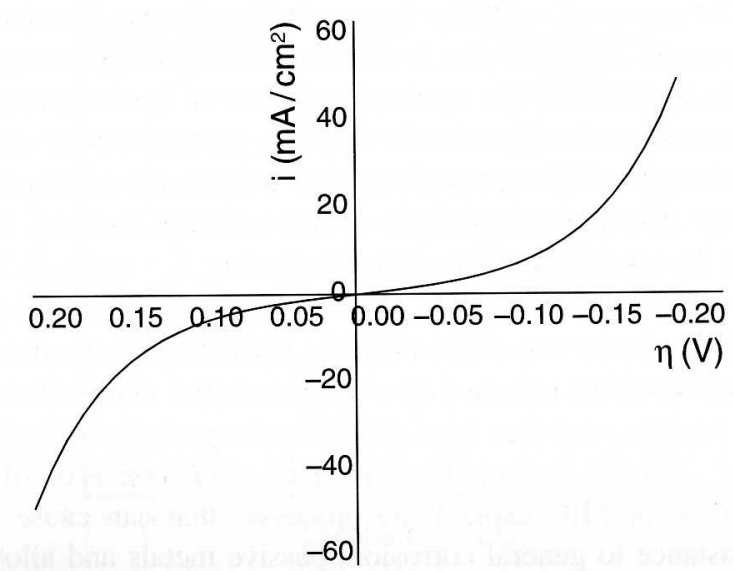

Fig. 1 Potentiodynamic polarization curve. The relationship between the overpotential $(\eta)$, which varied between -0.2 and $+0.2 \mathrm{~V}$, and the current density $(i)$ for $i_{0}=1 \mathrm{~mA} \mathrm{~cm}-2$ and $\alpha=0.5$ 


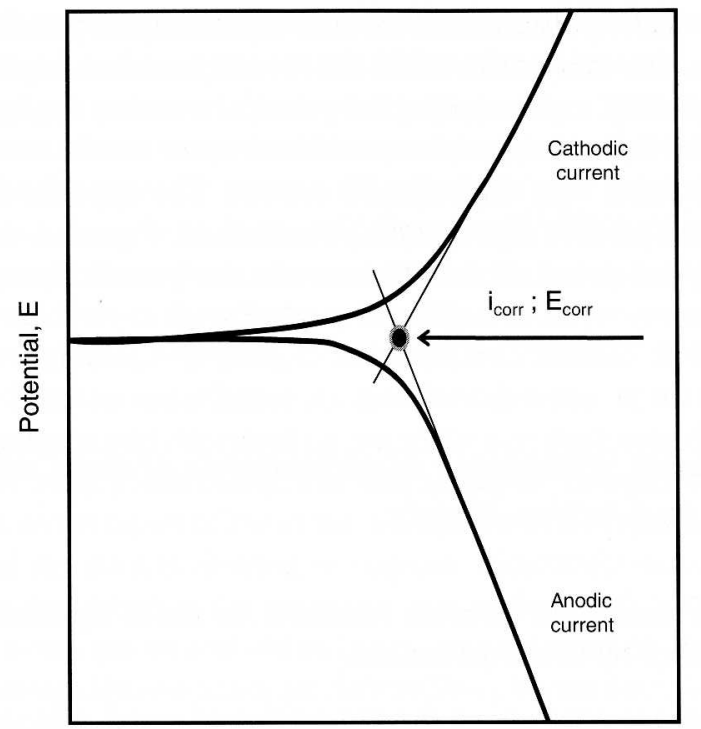

Log Current, log i

Fig. 2 The intersect of the extrapolated anodic and cathodic potentiodynamic polarization curves demonstrates the meaning of the corrosion potential, $E_{\text {corr }}$, and the corrosion current, $i_{\text {corr }}$. The corrosion potential, $E_{\text {corr }}$, can be measured with respect to a suitable reference electrode (see also Fig. 4 , where such a measurement is run for a real sample). The corrosion current, $i_{\text {corr }}$ cannot be measured directly, unless the anode and the cathode are separated, but it can be estimated using other electrochemical techniques based on disturbing the potential of the electrode

of the equilibrium for the relevant reactions. These interactions may also affect the kinetics of the process, e.g., by changing the concentrations of the reactants and products of the corrosion reactions, and thus the rates of the relevant reactions. All these interactions can be presented as in Fig. 2, or a similar plot can be created for specific reactions and reactants. If such a plot is used, modifications affecting the thermodynamics change the locations of the equilibrium points on the vertical axis. For example, replacing protons with oxygen as the cathodic reactant would raise the position of the equilibrium for the cathodic reactions. This would have an effect on the kinetics of the reaction by affecting the position of the intercept between the anodic and cathodic parts of the corrosion reaction, thus affecting $E_{\text {corr }}$ and $i_{\text {corr }}$. The kinetics of the participating reactions are illustrated as the slopes of the lines in Fig. 2. For example, a sudden increase in the rate of the cathodic reaction (higher cathodic current for the same potential) would be reflected by a decrease in the slope of the line representing the cathodic reaction, and thus by a change in the position of the intercept determining $E_{\text {corr }}$ and $i_{\text {corr }}$. Figure 2 shows the principles of the corrosion of active metals, and the mechanisms of MIC explain the processes that can cause such changes. Despite their resistance to general corrosion, passive metals and alloys can also be affected by MIC. To evaluate the mechanisms of such effects, we will first discuss the mechanisms of the corrosion of stainless steels and other passive metals and then, as we did for active metals, discuss the possible microbial effects that can modify these mechanisms and accelerate corrosion.

\section{Corrosion of Passive Metals}

Passive metals and alloys show a different mechanism of corrosion than active metals do. The best known passive alloys are stainless steels, and much research has been done on MIC of these materials. The corrosion reactions for stainless steels are the same as those for iron. However, stainless steels are alloys and some of their components, when oxidized, form dense layers of oxides, passive layers, which prevent further corrosion. Passivated alloys can resist corrosion in the presence of strong oxidants that would cause corrosion on unalloyed metal. However, this protection works to a certain extent only. When a cathodic reactant polarizing the metal has a high enough oxidation potential, localized corrosion, called pitting, occurs as a result of localized damage to the passive layer. The mechanism of this process is shown in Fig. 3.

As shown in Fig. 3, when a passivating alloy is subjected to anodic polarization, i.e., to an increasing electrode potential, the corrosion current initially increases, following the increase in the polarization potential. This increase continues until the polarization potential reaches a critical value, called the passivation potential. At this potential, the alloying constituents of the metal are oxidized and form dense layers on the metal surface, which slow down the corrosion of the metal, as is demonstrated by the decreasing corrosion current. As the polarization potential increases further, the metal first reaches a passive zone, in which it is immune to the increase in the polarization potential until the polarization potential reaches a critical value, called the pitting potential. When the polarization reaches, and exceeds, the pitting potential, the

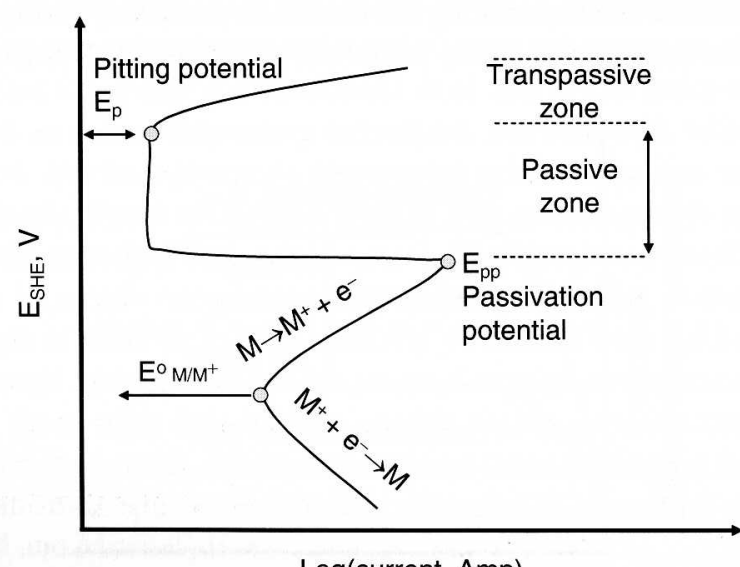

Log(current, Amp)

Fig. 3 Potentiodynamic polarization curve of a passive metal; thermodynamic principles of passivation and of pitting corrosion 
orrosion current gradually increases, as a result of localized damage to the passive ayers. The damaged areas are small compared to the surface of the metal; the damage 0 the surface has the form of small pits, and this type of corrosion is called pitting orrosion. Because the damaged areas become anodic sites, their small combined urface area makes the localized corrosion process particularly dangerous for the ntegrity of the metal. The anodic current densities can reach high values and localzed damage of the material can progress much faster than it does in cases of general orrosion, in which the anodic current densities are much smaller.

\section{| Microbially Stimulated Modifications of the Corrosion of Passive Metals and Alloys}

'assive metals and alloys, such as stainless steels, can be used within the passive one, where the oxidation potentials of the available oxidants do not exceed the itting potential. Microbial interference that may accelerate the corrosion of such urfaces is then necessarily related to two possible mechanisms:

Microbially generated oxidants (cathodic reactants) can have higher oxidation potentials than the pitting potential.

Microbially stimulated localized damage to the passive layers can decrease the pitting potential.

The first mechanism is related to the deposition of biomineralized manganese xides, which can subsequently raise the potential of the passive metal above the itting potential. The second mechanism is related to the damage of the passive netal surface by microorganisms in biofilms. We will discuss these mechanisms in nore detail later in this chapter.

Figure 4 shows the relation among the corrosion potential, pitting potential, and robability of pits initiation, redrawn from Sedriks (1996). The potential $\left(E_{\text {corr }}\right)$ of a

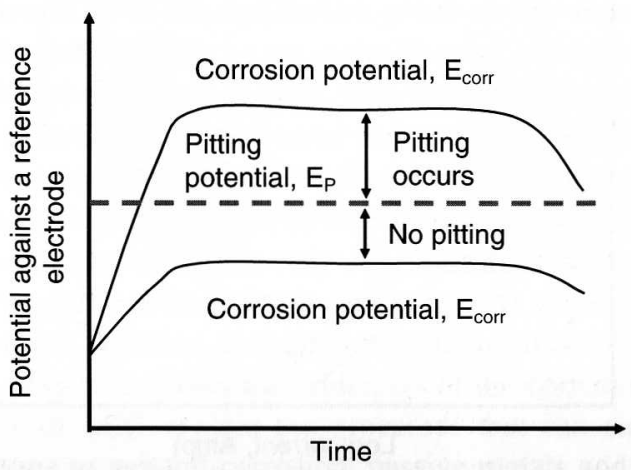

ig. 4 When the corrosion potential, $E_{\text {corr }}$, reaches the pitting potential, $E_{\mathrm{p}}$ (dashed line), of the letal in the given solution, pits are initiated (redrawn from Sedriks, 1996) metal such as stainless steel is measured against time. If the potential of the stainless steel is higher than the pitting potential $\left(E_{\mathrm{p}}\right)$, the stainless steel develops pits to initiate corrosion. If the potential of the stainless steel is less than the pitting potential, pits cannot develop. The pitting potential can be determined using standard electrochemical techniques described elsewhere (ASM Handbook Series 1987).

\section{Mechanisms by Which Metabolic Reactions in Biofilms can Interact with Corrosion Reactions}

\subsection{Mechanism 1: Biofilms Create Oxygen Heterogeneities}

The interaction between metabolic activity in biofilms and corrosion reactions appears to be trivial: microorganisms use the cathodic reactant, oxygen, which makes it unavailable for the corrosion reactions and, as a result, the corrosion rate decreases. If true, this mechanism would actually inhibit corrosion, and there is experimental evidence that this occurs in some situations. Hernandez et al. (1990) reported a decrease in the corrosion rate of mild steel in the presence of a uniform layer of biofilm. This decrease was attributed to the respiration of the biofilm microorganisms, resulting in a decline in oxygen concentration at the metal surface and an associated decrease in the rate of the cathodic reduction of oxygen. These authors reproduced their observations using synthetic seawater with Pseudomonas sp. S9 as well as with Serratia marcescens (Hernandez et al. 1994). We now know that to inhibit corrosion by this mechanism the biofilm must cover the surface of the metal uniformly and, in principle at least, must have uniformly distributed microbial activity. As biofilms are not uniform and microbial activity in biofilms is not uniformly distributed, this mechanism can be demonstrated in the laboratory but is unlikely to persist in a natural environment. Oxygen consumption rates and oxygen concentrations in biofilms vary from one location to another (Lewandowski et al. 1997; Lewandowski and Beyenal 2007); this leads to a more interesting interaction, mechanism 2 , which increases the rate of corrosion, and there is some experimental evidence for it as well. White et al (1985), for example, found no accumulation of iron or other metals in EPS from biofilms growing on corroding 304 stainless steel. They attributed the observed accelerated corrosion to an inhomogeneous distribution of biofilm at the metal surface resulting in areas of differing cathodic activity, consistent with a differential aeration cell. Areas covered with biofilm exhibit lowered oxygen concentrations and become anodic, while those with less biofilm exhibit higher oxygen concentrations anc become cathodic. As a result, anodic and cathodic areas are fixed at the metal surface and this mechanism is appropriately called corrosion as a result of differential aeration cells (Ford and Mitchell 1990).

Metal corrosion through the formation of differential aeration cells results from different concentrations of oxygen occurring at different locations on the meta surface. This effect, different concentrations of oxygen at different locations on the 
metal surface, can be caused by the active consumption of oxygen by microorganisms in biofilms nonuniformly distributed on the metal surface, but it can also be caused by a passive mechanism in which oxygen access to some areas is physically obstructed. Placing an o-ring on a metal surface is an example of such a mechanism, but other, more subtle, scenarios are possible as well. One such scenario is based on partially covering the metal surface with a material that has nonuniformly distributed diffusivity for oxygen. The access of oxygen to some locations on the metal surface is more difficult than its access to other locations on the same surface, and differential aeration cells are formed.

These speculations lead to the question of whether depositing microbial EPS on a metal surface can cause the formation of differential aeration cells, and to a more general question: what is the role of EPS in MIC? It is well known that polysaccharides, the main constituent of EPS, can be cross-linked with metal ions. In principle, then, if EPS covers a corroding site, the metal ions can cross-link the polysaccharides and affect the position of the equilibrium between the corroding metal and its ions, thus accelerating corrosion. This mechanism is analogous to the formation of differential aeration cells, and in corrosion science both mechanisms are called differential concentration cells. The metal concentration cells do not seem to affect MIC to a large extent, at least based on the report by White et al. (1985), who found no accumulation of iron or other metals in EPS from biofilms growing on corroding 304 stainless steel. Doubt remains about the passive effect of EPS, in which it changes the access of oxygen to various locations on the metal surface. Can differential aeration cells be formed by this mechanism?

To address this question, we will first discuss the thermodynamic principles of corrosion by differential aeration cells and determine the factors that must be measured to resolve whether this mechanism is active in biofilms.

If the anodic reaction is the oxidation of iron: $\mathrm{Fe} \rightarrow \mathrm{Fe}^{2+}+2 \mathrm{e}^{-}$, and the cathodic reaction is the reduction of oxygen: $\mathrm{O}_{2}+2 \mathrm{H}_{2} \mathrm{O}+4 \mathrm{e}^{-} \rightarrow 4 \mathrm{OH}^{-}$, then the overall reaction describing the process is

$$
2 \mathrm{Fe}+\mathrm{O}_{2}+2 \mathrm{H}_{2} \mathrm{O} \rightarrow 2 \mathrm{Fe}^{2+}+4 \mathrm{OH}^{-}
$$

The Nernst equation quantifying the potential for this reaction is

$$
E=E^{0}-\frac{0.059}{4} \log \frac{\left[\mathrm{Fe}^{2+}\right]^{2}\left[\mathrm{OH}^{-}\right]^{4}}{p\left(\mathrm{O}_{2}\right)}
$$

If the oxygen concentrations at two adjacent locations on an iron surface are different, then the cell potentials at these locations are different as well. Specifically, the location where the oxygen concentration is higher will have a higher potential (more cathodic) than the location where the oxygen concentration is lower (more anodic). The difference in potential will give rise to current flow from the anodic locations to the cathodic locations and to the establishment of a corrosion cell. This is the mechanism of differential aeration cells, and the prerequisite to this mechanism is that the concentration of oxygen vary among locations (Acuna et al. 2006; Dickinson and Lewandowski 1996; Hossain and Das 2005). Indeed, many measurements using oxygen microsensors have demonstrated that oxygen concentrations in biofilms can vary from one location to another (Lewandowski and Beyenal 2007).

This mechanism by which differential aeration cells are formed, in which a thin layer of biofilm at the surface of the substratum is discontinuous, is consistent with the current model of biofilm structure, shown in Fig. 5.

One of the most dangerous forms of localized corrosion of mild steel is tuberculation, which is the development or formation of small mounds of corrosion products. According to Herro (1991), tubercle formation originates from a differential oxygen concentration cell.

\subsection{Mechanism 2: Biofilm Matrix Increases the Mass Transport Resistance near the Metal Surface, Thus Changing the Kinetics of the Corrosion Processes}

Once the mechanism of differential aeration cell formation in biofilms had been demonstrated and explained, the immediately following question was whether microbial activity in biofilms is a necessary prerequisite to the formation of differential aeration cells, or perhaps, the presence of extracellular polymeric substances on the surface suffices. The idea that the presence of EPS on the surface might suffice is related to the known mechanisms of corrosion initiation based on different resistances to mass transport for oxygen at various locations on metal surfaces, similar to the initial stages of crevice formation. The possibility that the active removal of oxygen by the biofilm microorganisms might not be necessary to initiate a differential aeration cell was discussed by MIC researchers, but it was usually dismissed on the grounds that extracellular polymers are composed of $98 \%$ water and their layers on metal surfaces are only a few hundred micrometers thick, so that
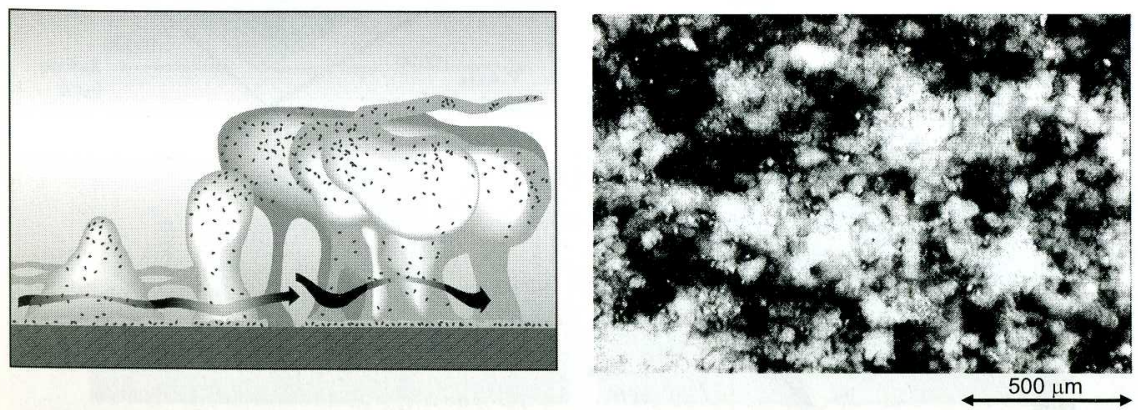

Fig. 5 Conceptual structure of biofilms (left) and a light microscopy image of a biofilm (right) 
the increase in diffusion resistance expected as a result of depositing extracellular polymer could not possibly be significant. Nevertheless, the hypothesis was formulated that the deposition of extracellular polymer on a metal surface might form differential aeration cells, and an appropriate experiment was designed and executed (Roe et al. 1996). As a model of extracellular polymer, calcium alginate was used. Alginate is an extracellular biopolymer excreted by biofilm microorganisms. If alginate initiates the differential aeration cell, then the oxygen concentrations at the locations covered with alginate should be higher than those at the locations not covered with alginate. Also, $\mathrm{pH}$ at the locations covered with alginate should be higher than that at locations not covered with alginate. These expectations are consistent with the anodic and cathodic reactions, in which the anodic reaction decreases $\mathrm{pH}$ because ferrous ions hydrolyze and precipitate as hydroxides, and the cathodic reaction increases $\mathrm{pH}$ because it consumes protons. Two drops of sodium alginate were deposited on the surface of a corrosion coupon made of mild steel and exposed to a calcium solution which cross-linked the sodium alginate and formed a calcium alginate gel on the surface. To test whether depositing calcium alginates can initiate differential aeration cells, the variations in oxygen concentration and $\mathrm{pH}$ above these spots were measured using scanning microelectrodes. In addition, a scanning vibrating electrode (SVE) was used to determine the distribution of the electrical field above the surface, and it was expected that this electrode would detect the positions of the anodic and cathodic sites. The results, shown in Fig. 6
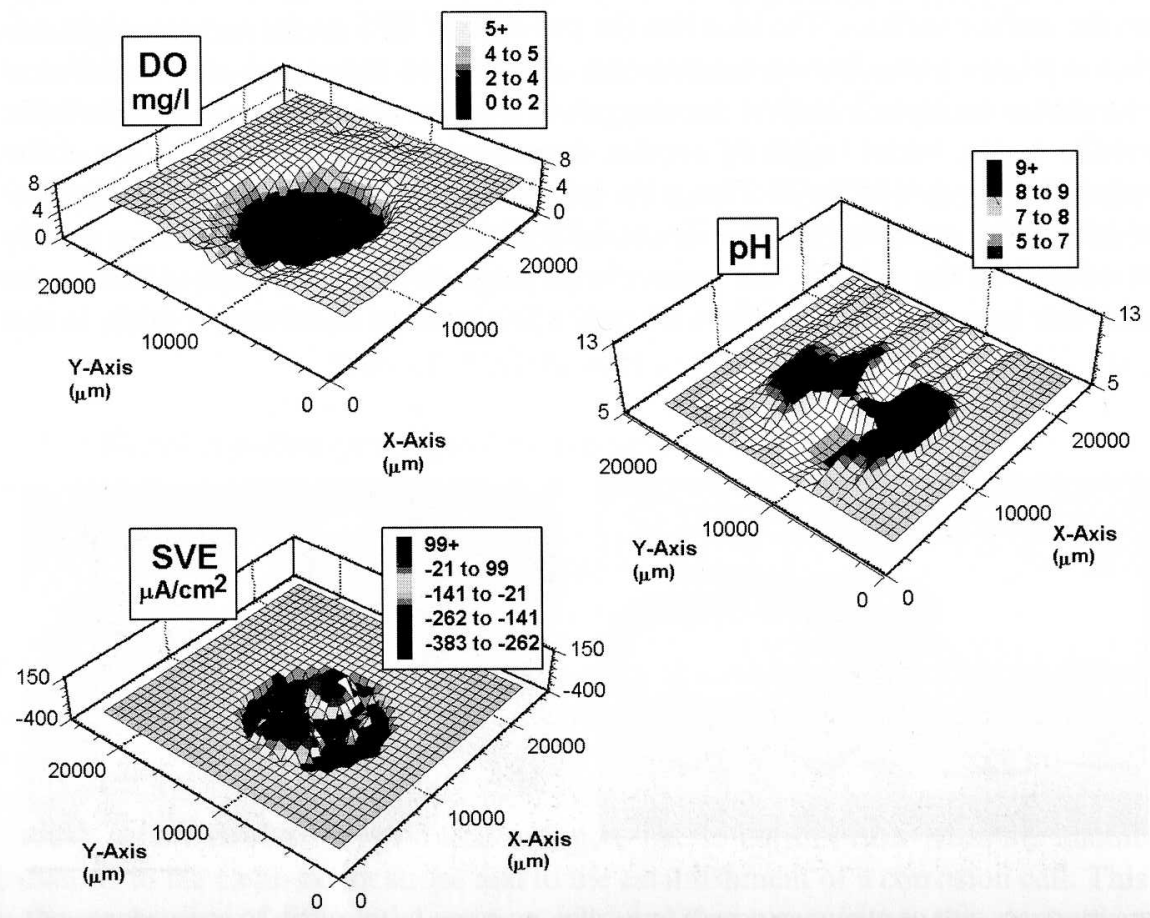

Fig. 6 Two spots of calcium alginate deposited on a surface of mild steel fix anodic sites (Roc et al. 1996) demonstrated that the mere deposition of a thin layer of alginate on mild steel is enough to fix the anodic sites and initiate corrosion. All the characteristics of differential aeration cells were present in the system: $\mathrm{pH}$ was lower near the sites covered with alginate than near the sites not covered; oxygen concentration was lower near the sites not covered; and, as demonstrated by the image of the electric field distribution provided by the scanning vibrating electrode, there were anodic and cathodic sites fixed at the surface of the metal. This result, somewhat unexpected at that time, had further implications: it demonstrated that merely killing biofilm microorganisms using biocide(s) or antimicrobial(s) does not necessarily stop MIC. Once the biopolymer has been deposited on the surface, the active consumption of oxygen in the respiration reaction enhances the formation of differential aeration cells, but even without it, differential aeration cells can be formed just because EPS has been deposited on the surface. This conclusion coincides with the general notion that removing the biofilmis more important than killing the biofilm microorganisms.

Once the differential aeration cell has been established, the corrosion proceeds according to the mechanism described by (Eq. 18), which is also illustrated in Fig. 7.

\subsection{Mechanism 3: Metabolic Reactions in Biofilms Generate Corrosive Substances, Exemplified by the Sulfate-Reducing Bacteria Corrosion of Mild Steels}

The mechanism of MIC due to the formation of differential aeration cells can be called a nonspecific one, because it does not depend on the physiology of the microorganisms that deposited the extracellular polymers. There are, however, other mechanisms that are closely related to the type of microorganisms active in the biofilm and to their metabolic reactions (Beech and Gaylarde 1999; Romero et al. 2004; Videla and Herrera 2005; Xu et al. 2007). An example of such a mechanism is sulfate-reducing bacteria (SRB) corrosion (Ilhan-Sungur et al. 2007; Lee et al. 1995).
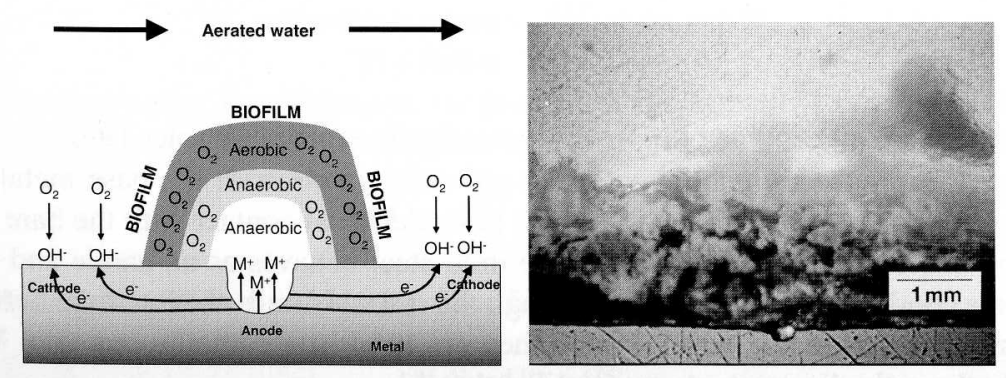

Fig. 7 (a) Biofilm heterogeneity results in differential aeration cells. This schematic shows pit initiation due to oxygen depletion under a biofilm (Borenstein 1994). (b) An anodic site and pit under the biofilm and corrosion products deposited on mild steel 
The corrosion of mild steel caused by SRB is probably the most celebrated case MIC because it provides a direct, and easy to understand, link between microbial actions and electrochemistry (Javaherdashti 1999). Despite the progress in search, and in understanding of the process, little has been done to prevent or stop is type of corrosion once initiated, and SRB corrosion is still considered the main pe of MIC. For example, Bolwell in 2006 demonstrated that engine failures in gas rbines were caused by SRB growing in the seawater lubricating oil coolers and intaminating it (Bolwell 2006). The overall progress in understanding of MIC, wwever, allows us to implicate other microorganisms as partners of SRB and nsider more complex scenarios of MIC, in which two types of microorganisms odify the potential of the electrode in the opposite directions. For example, Rao

al. (2000) found that in the cooling water system of a nuclear test reactor ironid manganese-oxidizing bacteria (MOB) (Leptothrix sp.) and SRB (Desulfovibrio ).) were responsible for the corrosion of carbon steel. It is interesting to notice that ese two types of microorganisms drive the redox potential in the opposite rections, thus increasing the gap between the potential of the anodic reaction and ie potential of the cathodic reaction.

SRB produce hydrogen sulfide by reducing sulfate ions (Videla and Herrera 005). According to the mechanism that was proposed by Von Wohlzogen Kuhr in 934 , SRB oxidize cathodically generated hydrogen to reduce sulfate ions to $\mathrm{H}_{2} \mathrm{~S}$, lereby removing the product of the cathodic reaction and stimulating the progress $f$ the reaction (Al Darbi et al. 2005). Over the years it became obvious that the lechanism must be more complex than that initially suggested, and it is now cerin that the possible pathways for cathodic reactions are more complex and can, or example, include sulfides and bisulfides as cathodic reactants (Videla 2001; Tidela and Herrera 2005).

Hydrogen sulfideitself can be a cathodic reactant (Antony et al. 2007; Costello 974):

$$
2 \mathrm{H}_{2} \mathrm{~S}+2 \mathrm{e}^{-} \rightarrow \mathrm{H}_{2}+2 \mathrm{HS}
$$

7errous iron generated from anodic corrosion sites (21) precipitates with the metaolic product of microbial metabolism, hydrogen sulfide, forming iron sulfides, $\mathrm{zeS}_{x}$

$$
\mathrm{Fe}^{2+}+\mathrm{HS}^{-}=\mathrm{FeS}+\mathrm{H}^{+}
$$

This reaction may provide protons for the cathodic reaction (Crolet 1992).

The precipitated iron sulfides form a galvanic couple with the base metal. For corrosion to occur, the iron sulfides must have electrical contact with the bare steel surface. Once contact is established, the mild steel behaves as an anode and elecrons are conducted from the metal through the iron sulfide to the interface between he sulfide deposits and water, where they are used in a cathodic reaction. What exactly the cathodic reactants are is still debatable.

Surprisingly, the most notorious cases of SRB corrosion often occur in the nroconne of nvvaen Since the SRB are anaerobic microorganisms, this fact has been difficult to explain. Our group believes that this effect is based on mechanism 3: iron sulfides (resulting from the reaction between iron ions and sulfide and bisulfide ions) are oxidized by oxygen to elemental sulfur, a substance known to be a strong corrosion agent (Lee et al.1995). Biofilm heterogeneity plays an important role in this process, because the central parts of microcolonies are anaerobic while the outside edges remain aerobic (Lewandowski and Beyenal 2007). This arrangement makes this mechanism possible because the oxidation of iron sulfides produces highly corrosive elemental sulfur, as illustrated by the following reaction:

$$
2 \mathrm{H}_{2} \mathrm{O}+4 \mathrm{FeS}+3 \mathrm{O}_{2} \rightarrow 4 \mathrm{~S}^{0}+4 \mathrm{FeO}(\mathrm{OH})
$$

Hydrogen sulfide can also react with the oxidized iron to form ferrous sulfide and elemental sulfur (Schmitt 1991), thereby aggravating the situation by producing even more elemental sulfur, and closing the loop through production of the reactant in the first reaction, $\mathrm{FeS}$.

$$
3 \mathrm{H}_{2} \mathrm{~S}+2 \mathrm{FeO}(\mathrm{OH}) \rightarrow 2 \mathrm{FeS}+\mathrm{S}^{0}+4 \mathrm{H}_{2} \mathrm{O}
$$

The product of these reactions - elemental sulfur - accelerates the corrosion rate. Schmitt (1991) has shown that the corrosion rate caused by elemental sulfur can reach several hundred mils per year. We have demonstrated experimentally that elemental sulphur is deposited in the biofilm during the SRB corrosion (Nielsen et al. 1993). It is also well known that sulfur disproportionation reaction that produces sulfuric acid and hydrogen sulfide is carried out by sulfur disproportionating microorganisms (Finster et al. 1998):

$$
4 \mathrm{~S}^{0}+4 \mathrm{H}_{2} \mathrm{O} \rightarrow 3 \mathrm{H}_{2} \mathrm{~S}+\mathrm{H}_{2} \mathrm{SO}_{4}
$$

In summary, according to this mechanism, SRB corrosion of mild steel in the presence of oxygen is an acid corrosion:

$$
\begin{aligned}
& \text { anodic reaction: } \mathrm{Fe} \rightarrow \mathrm{Fe}^{2+}+2 \mathrm{e}^{-} \\
& \text {cathodic reaction: } 2 \mathrm{H}^{+}+2 \mathrm{e}^{-} \rightarrow \mathrm{H}_{2}
\end{aligned}
$$

It is worth noticing that hydrogen, the product of the cathodic reaction, can be oxidized by some species of SRB to reduce sulfate and generate hydrogen sulfide, $\mathrm{H}_{2} \mathrm{~S}$ :

$$
\mathrm{H}_{2} \mathrm{SO}_{4}+4 \mathrm{H}_{2} \rightarrow \mathrm{H}_{2} \mathrm{~S}+4 \mathrm{H}_{2} \mathrm{O}
$$

Hydrogen sulfide dissociates to bisulfides:

$$
\mathrm{H}_{2} \mathrm{~S}=\mathrm{H}^{+}+\mathrm{HS}^{-}
$$

which are used in the reaction described by (20) 
Thus, this mechanism involves several loops in which reactants are consumed and regenerated, and the process continues at the expense of the energy released by the oxidation of the metal.

These reactions are linked with each other in a network of relations. To illustrate the main pathways, Fig. 8 shows the main reactions and the effect of oxygen on the SRB corrosion of mild steel.

\subsection{Mechanism 4: Metabolic Reactions in Biofilms Generate Substances That Serve as Cathodic Reactants}

One of the most puzzling aspects of MIC is the change in electrochemical properties of stainless steel that occurs as the metal surface is colonized by microorganisms in natural water. The dominant effects of colonization are a several-hundred-millivolt increase in corrosion potential $\left(E_{\text {corr }}\right)$ to values near $+350 \mathrm{mV}$ versus the saturated calomel electrode (SCE) and 2-3 orders of magnitude increase in cathodic current density at potentials between approximately -300 and $+300 \mathrm{mV}_{\mathrm{SCE}}$. These effects, known as ennoblement, were first observed in the mid-1960s (Crolet 1991, 1992). Since then, numerous researchers (Braughton et al. 2001; Dickinson et al. 1997; Linhardt 2006; Washizu et al. 2004) have shown that stainless steels and other passive metals in natural waters exhibit a several-hundred-millivolt increase in corrosion potential, accompanied by an increase in cathodic current drawn, upon mild polarization. This phenomenon has been observed in a wide variety of natural and engineered environments. Washizu et al. (2004), Mattila et al. (1997), and Dexter and Gao (1988) described ennoblement in seawater (Amaya and Miyuki 1994), Dickinson et al.

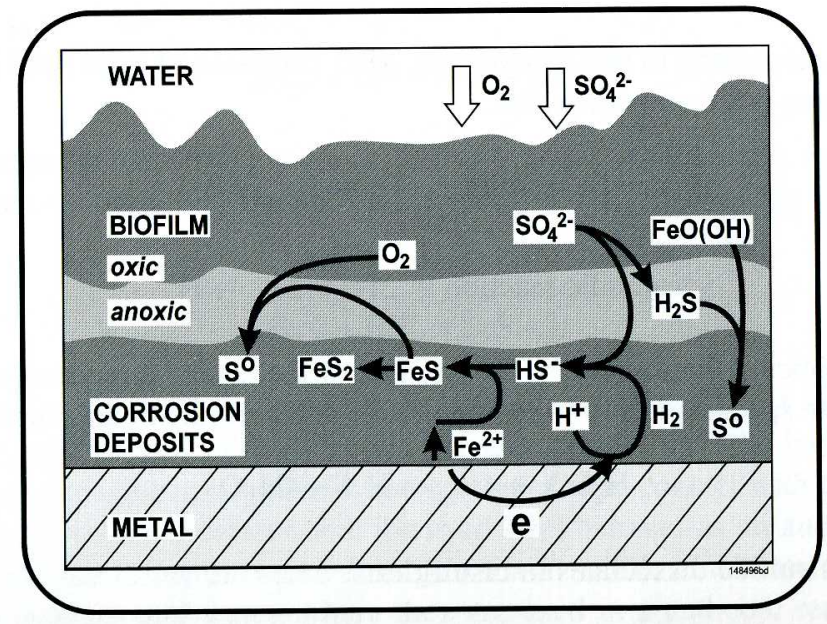

Fig. 8 Sulfate-reducing bacteria corrosion of mild steel in the presence of oxygen is an acid corrosion (Lewandowski et al. 1997) (1996a) reported its occurrence in a freshwater stream, and Linhardt (1996) reported it in a hydroelectric power plant.

The ennoblement of stainless steels in natural waters may influence material integrity: as the corrosion potential approaches the pitting potential, the material integrity may be compromised by localized (pitting and crevice) corrosion. This sequence of events, from an increase in corrosion potential to pit initiation, is well known to material scientists, although the microbial component is new. Because the pitting potential of $316 \mathrm{~L}$ stainless steel in seawater is around $200 \mathrm{mV}_{\mathrm{SCE}}$, the danger of pitting initiation in such an environment is serious. There are, however, reports of microbial involvement in pitting corrosion of stainless steels immersed in fresh waters of much lower chloride concentration than that found in seawater (Hakkarainen 2003; Linhardt 2004, 2006; Olesen et al. 2001).

Temporal changes in the corrosion potential of $316 \mathrm{~L}$ stainless steel coupons immersed in different natural water sources are illustrated by our results in Fig. 9. In all cases the potentials of $316 \mathrm{~L}$ stainless steel coupons increased, demonstrating ennoblement of the stainless steel. Several hypotheses have been postulated to explain the mechanism of ennoblement, all suggesting that it is caused by microbial colonization of the metal surface. Mollica and Trevis (1976) attributed ennoblement to microbially produced extracellular polymeric substances. Dexter and Gao (1988) suggested that acidification of the metal-biofilm interface caused by protons derived from the metabolic reactions in the biofilm increased the potential. Chandrasekaran and Dexter (1993) proposed a combination of acidification and hydrogen peroxide production. Eashwar and Maruthamuthu (1995) believed that ennoblement was caused by microbially produced passivating siderophores. Although many authors have demonstrated

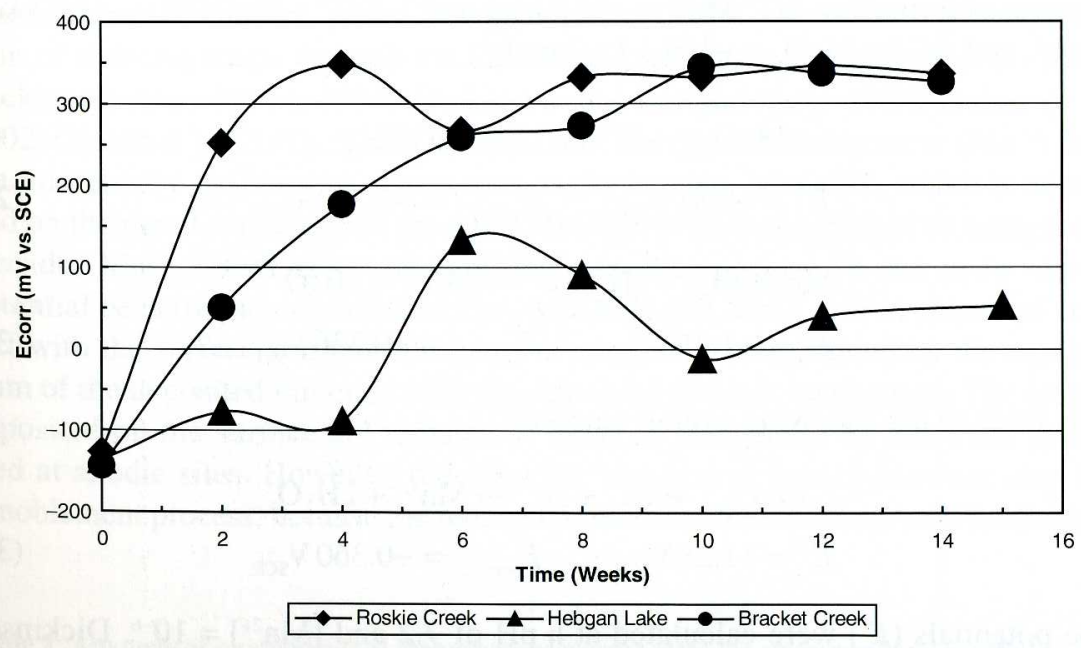

Fig. 9 Potential of 316L stainless steel coupons exposed to fresh water at three locations in Montana for 4 months. The rate and extent of ennoblement roughly correlate with the amount of biomineralized manganese recovered from the surface after 4 months (Table 1) (Braughton et al. 2001) 
the relationship between ennoblement and biofilm formation, the proposed hypotheses have not been supported by convincing experimental evidence unequivocally demonstrating the mechanism of ennoblement.

We have demonstrated, in the laboratory and in the field, that stainless steels and other passive metals ennoble when colonized by MOB (Braughton et al. 2001; Dickinson et al. 1996a, 1997; Dickinson and Lewandowski 1996). While the origin of the manganese-rich material deposited on stainless steel coupons exposed to Bozeman stream water was not rigorously established, mineralencrusted bacterial sheaths characteristic of Leptothrix sp. and mineralized capsules characteristic of Siderocapsa treubii were abundant on the surface of the ennobled stainless steel coupons, and MOB were isolated from the manganeserich deposits (Dickinson and Lewandowski 1996). In parallel with these findings, Linhardt (1996) also demonstrated that manganese-oxidizing biofilms were responsible for pitting corrosion of stainless steel. Although biomineralization of manganese can be carried out by certain genera of the so-called iron and manganese group - Siderocapsa, Leptothrix, and Crenothrix - in fact the property is widely distributed in a variety of organisms, including bacteria, yeast, and fungi (Caspi et al. 1998; Francis and Tebo 2002; Tebo et al. 1997, 2004, 2005). These organisms can oxidize dissolved manganese to form highly enriched mineralbiopolymer encrustations. Deposits of manganese oxides form on submerged materials, including metal, stone, glass, and plastic, and can occur in natural waters and sediments with manganese levels as low as 10-20 ppb (Dickinson et al. 1996a, 1997; Dickinson and Lewandowski 1996).

Because biomineralized manganese oxides are in direct electrical contact with the metal, the metal exhibits the equilibrium dissolution potential of the oxides. The standard potentials $\left(E^{0}\right)$ for (Eq. 29)-(Eq. 31) were calculated using the following energies of formation: $\Delta G_{\mathrm{f}}^{\circ} \mathrm{Mn}^{2+}=-54.5 \mathrm{kcal} \mathrm{mol}^{-1}, \Delta G_{\mathrm{f}}^{\circ} \gamma-\mathrm{MnOOH}=-133.3 \mathrm{kcal}$ $\mathrm{mol}^{-1}$, and $\Delta G_{\mathrm{f}}^{\circ} \gamma-\mathrm{MnO}_{2}=-109.1 \mathrm{kcal} \mathrm{mol}^{-1}$.

$$
\begin{gathered}
\mathrm{MnO}_{2(\mathrm{~s})}+\mathrm{H}^{+}+\mathrm{e}^{-} \rightarrow \mathrm{MnOOH}_{(\mathrm{s})} \\
E^{0}=+0.81 \mathrm{~V}_{\mathrm{SCE}} \quad E_{\mathrm{pH}=7.2}^{\prime}=+0.383 \mathrm{~V}_{\mathrm{SCE}} \\
\mathrm{MnOOH}_{(\mathrm{s})}+3 \mathrm{H}^{+}+\mathrm{e}^{-} \rightarrow \mathrm{Mn}^{2+}+2 \mathrm{H}_{2} \mathrm{O} \\
E^{0}=+1.26 \mathrm{~V}_{\mathrm{SCE}} \quad E_{\mathrm{pH}=7.2}^{\prime}=+0.336 \mathrm{~V}_{\mathrm{SCE}}
\end{gathered}
$$

This leads to the following overall reaction:

$$
\begin{gathered}
\mathrm{MnO}_{2(\mathrm{~s})}+4 \mathrm{H}^{+}+2 \mathrm{e}^{-} \rightarrow \mathrm{Mn}^{2+}+2 \mathrm{H}_{2} \mathrm{O} \\
E^{0}=+1.28 \mathrm{~V}_{\mathrm{SCE}} \quad E_{\mathrm{pH}=7.2}^{\prime}=+0.360 \mathrm{~V}_{\mathrm{SCE}}
\end{gathered}
$$

The potentials $\left(E^{\prime}\right)$ were calculated at a $\mathrm{pH}$ of 7.2 and $\left[\mathrm{Mn}^{2+}\right]=10^{-6}$. Dickinson et al. (1996a) demonstrated that just a $6 \%$ surface coverage by manganese oxides can increase the resting open circuit potential (OCP) of stainless steels $\left(-200 \mathrm{mV}_{\mathrm{SCE}}\right.$ ) by some $500 \mathrm{mV}$, which coincides closely with the reported equilibrium potential of the oxides, $+362 \mathrm{mV}_{\mathrm{SCE}}$ at a $\mathrm{pH}$ of 7.2 (Dickinson and Lewandowski 1996; Linhardt 1998).

The thermodynamic calculations are in good agreement with the observations as the potential of stainless steel coupons exposed to river water rises to about $360 \mathrm{mV}$, as predicted. Our results directly correlate the extent and rate of ennoblement with the amount and rate of manganese oxides deposition on metal surfaces (Braughton et al. 2001). To determine which environmental factors influence the rate of ennoblement, we exposed $316 \mathrm{~L}$ stainless steel coupons at three locations, two creeks and a lake, for 100 days. The open circuit potential was monitored periodically, about once a week (Fig. 9). The coupons in both creeks reached a potential of $+350 \mathrm{mV}_{\mathrm{SCE}}$ in 3 weeks. The coupons in the lake reached a final potential of less than $+100 \mathrm{mV}_{\mathrm{SCE}}$ and the ennoblement rate was very slow. Manganese oxides were deposited on all metal coupons, and their amounts roughly correlated with the rate of ennoblement, as can be seen in Table 1 .

Figure 10 shows the potentiodynamic polarization curves of nonennobled, fully ennobled, and $\mathrm{MnO}_{2}$-plated stainless steel coupons. Both the microbial ennoblement and electroplating of $\mathrm{MnO}_{2}$ on the metal surface shift corrosion potentials by $-300 \mathrm{mV}$ in the noble direction and cause a corresponding increase in cathodic current density at modest overpotentials (around $-100 \mathrm{mV}$ ).

In our laboratory, Dickinson and colleagues studied the effects of MOB on stainless steels and demonstrated that 3-5\% surface coverage by biofouling deposits was enough to ennoble 316L stainless steel (Dickinson et al. 1996a, 1997; Dickinson and Lewandowski 1998). Chemical examination of the deposits showed the presence of $\mathrm{Fe}$ (III) and $\mathrm{Mn}$ (IV), while epifluorescence microscopy revealed the presence of manganese- and iron-oxidizing bacteria (Dickinson and Lewandowski 1998). On the basis of these observations and other studies conducted in our laboratory, we have suggested that MOB are involved in the corrosion of stainless steels through the following mechanism (Braughton et al. 2001; Dickinson et al. 1996a, 1997; Dickinson and Lewandowski 1996; Geiser et al. 2002; Olesen et al. 2000a; Shi et al. 2002a,b): the divalent manganese $\left(\mathrm{Mn}^{2+}\right)$ ions are microbially oxidized to manganese oxyhydroxide, $\mathrm{MnOOH}$, which is deposited on the metal surface; then the solid $\mathrm{MnOOH}$ is further oxidized to manganese dioxide, $\mathrm{MnO}_{2}$. Both reactions contribute to the increase in the open circuit potential because the deposited oxides, $\mathrm{MnOOH}$ and $\mathrm{MnO}_{2}$, are in electrical contact with the surface and their dissolution potential is determined by the equilibrium of the deposited minerals with the dissolved divalent manganese. The oxides deposited on the surface are reduced to divalent manganese by electrons generated at anodic sites. However, reducing the manganese oxides does not stop the ennoblement process, because the reduced products of this reaction, soluble divalent

Table 1 Amounts of biomineralized manganese recovered from the surfaces after 4 months

\begin{tabular}{llll} 
Source & Bracket creek & Roskie creek & Hebgen lake \\
\hline Mn recovered $\left(\mu \mathrm{g} / \mathrm{cm}^{2}\right)$ & 9.3 & 33.6 & 1.7 \\
\hline
\end{tabular}




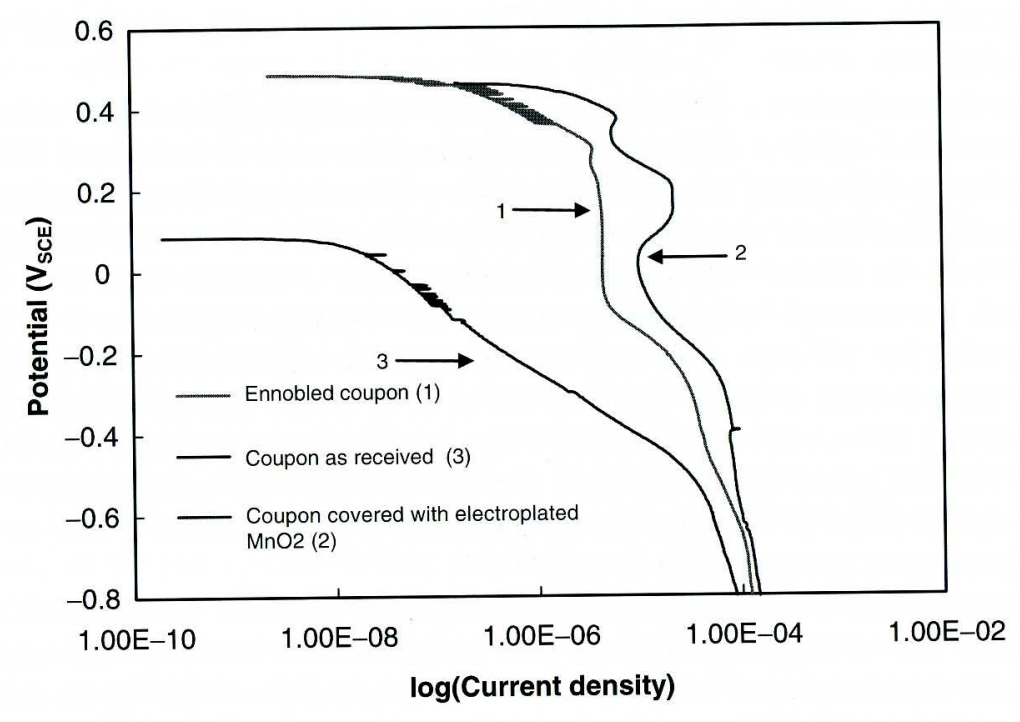

Fig. 10 Potentiodynamic polarization curves (316L stainless steel, $0.01 \mathrm{M} \mathrm{Na}_{2} \mathrm{SO}_{4}$, $\mathrm{pH} 8.30$; scan rate: $0.167 \mathrm{mV} \mathrm{s}^{-1}$ ) show typical behavior of nonennobled, fully ennobled, and $\mathrm{MnO}_{2}$-plated stainless steel coupons. (1) Biomineralized manganese on graphite electrode, (2) electrochemically deposited manganese oxides on graphite electrode, (3) clean graphite electrode used to reduce oxygen only. Both microbial ennoblement and $\mathrm{MnO}_{2}$ electroplating of the metal surface shift corrosion potentials by $\sim 300 \mathrm{mV}$ in the noble direction and cause a corresponding increase in cathodic current density at modest overpotentials (around $-100 \mathrm{mV}$ )

manganese ions, are reoxidized by the MOB attached to the metal surface. The described sequence of events, oxidation-reduction-oxidation of manganese, is a hypothetical mechanism that produces renewable cathodic reactants, $\mathrm{MnOOH}$ and $\mathrm{MnO}_{2}$, and their presence on the metal surface endangers material integrity. This mechanism is illustrated in Fig. 11.

The suggested mechanism relies on the activity of MOB in biofilms deposited on metal surfaces. The biomineralization of manganese can be carried out by a variety of organisms, including bacteria, yeast, and fungi, but it is particularly associated with genera of the so-called iron and manganese group - Siderocapsa, Gallionella, Leptothrix-Sphaerotilus, Crenothrix, and Clonothrix. These bacteria accelerate the oxidation of dissolved iron and manganese to form highly enriched mineral-biopolymer encrustations. Deposits form on submerged materials, including metal, stone, glass, and plastic, in natural waters with manganese levels as low as $10-20 \mathrm{ppb}$.

Biomineralized manganic oxides are efficient cathodes and increase cathodic current density on stainless steel by $2-3$ orders of magnitude at potentials between roughly -200 and $+400 \mathrm{mV}_{\mathrm{SCE}}$. The extent to which the elevated current density can be maintained is controlled by the electrical capacity of the mineral, which reflects both total accumulation and the conductivity of the mineral-biopolymer assemblage (only material in electrical contact with the metal will be cathodically active).

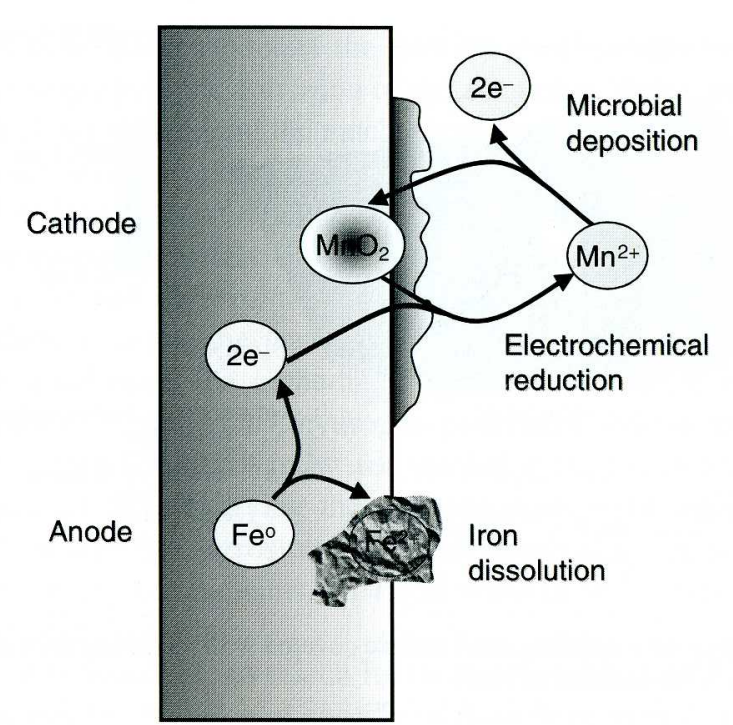

Fig. 11 Redox cycling on metal surfaces: hypothetical mechanism of microbial involvement in the corrosion of stainless steels and other passive metals (Olesen et al. 2000a)

Oxide accumulation is controlled by the biomineralization rate and by the corrosion current, in that high corrosion currents will discharge the oxide as rapidly as it is formed. It appears that this mechanism may result in redox cycling of manganese on metal surfaces, producing a renewable cathodic reactant, which agrees well with the notion that whenever biofilms accumulate on cathodic members of galvanic couples, a significant increase in the reduction current can be expected (Chandrasekaran and Dexter 1993). In conclusion, the accumulation of manganese oxides can cause pitting corrosion, as demonstrated in Fig. 12.

\subsection{Further Implications}

Our observations also suggest that MOB may be directly involved in pit initiation, in addition to the indirect effects caused by the biomineralized manganese oxides (Geiser et al. 2002). Scanning electron microscopy and atomic force microscopy images (Fig. 13) show micropits formed on 316L stainless steel ennobled by $L$. discophora SP-6. This indicates that the pits were initiated at the sites of bacterial attachment and then propagated because of the presence of manganese oxides driving the potential in the noble direction.

Our data show that the manganese oxides deposited on the surface elevate the potential, create an environment where the pits initiated by microbes can not repassivate. Because the pits are initiated at the sites of attachment, in this light, it appears that the bacteria initiate the pits and the microbially deposited manganese oxides stabilize the growth of the pits by maintaining a high potential. 


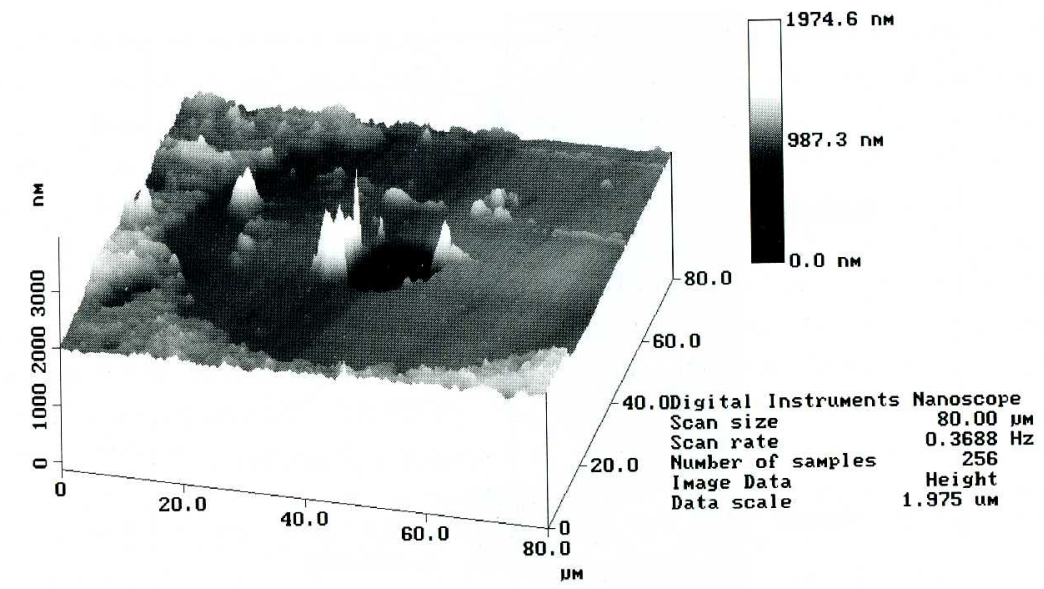

Fig. 12 Corrosion pit on a stainless steel surface covered with biomineralized manganese oxides and immersed in a $3.5 \%$ solution of $\mathrm{NaCl}$
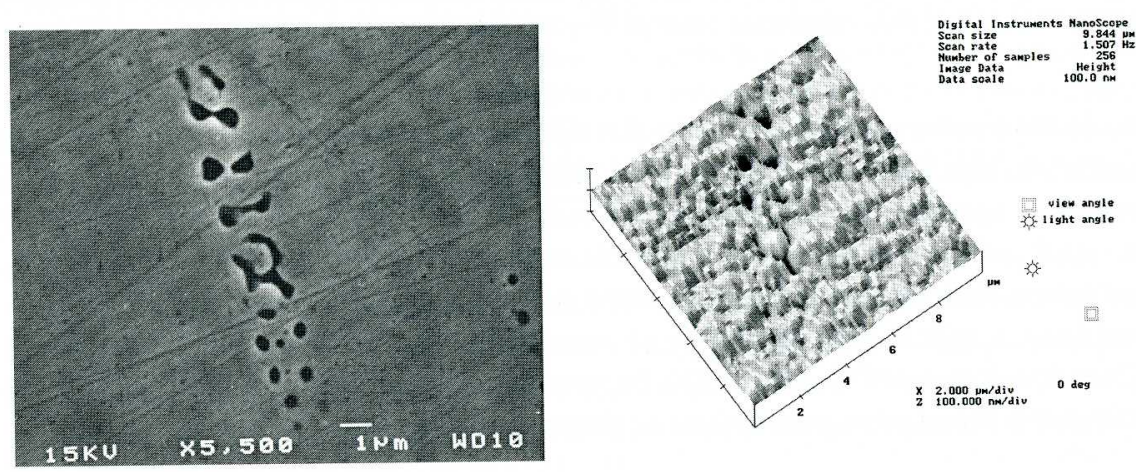

Fig. 13 Scanning electron microscopy and atomic force microscopy images of damage to a surface caused by colonization by manganese-oxidizing bacteria $L$. discophora SP-6 growing on $316 \mathrm{~L}$ stainless steel surface. The size and shape of the indentations closely resemble the size and shape of the microorganism colonies on the surface (Geiser et al. 2002)

\section{Summary and Conclusions}

In conclusion, we have demonstrated that biofilms can influence the corrosion of metals (1) by metabolic reactions in the biofilms consuming oxygen, the cathodic reactant; (2) by controlling the mass transport of the corrosion reactants and products, therefore changing the kinetics of the corrosion process; (3) by generating corrosive substances; and (4) by generating substances that serve as auxiliary cathodic reactants. These interactions do not exhaust the possible mechanisms by which biofilm
microorganisms may affect the corrosion of metals; rather, they represent those few instances in which we understand the mechanism from the thermodynamic point of view. In addition, we can use electrochemical and chemical measurements to detect one or more of their products. Other mechanisms implicated in MIC involve bacteria that produce corrosive metabolites. For example Thiobacillus thiooxidans produces sulfuric acid and Clostridium aceticum produces acetic acid. These two metabolic products dissolve the passive layers of oxides deposited on the metal surface, which accelerates the cathodic reaction rate (Borenstein 1994). Other mechanisms may be initiated by hydrogen-generating microorganisms causing hydrogen embrittlement of metals or by iron-oxidizing bacteria, such as Gallionella. An important aspect of quantifying these mechanisms is to demonstrate exactly how they interfere with the corrosion processes. There is no universal mechanism of MIC. Instead, many mechanisms exist and some of them have been described and quantified better than others.

It does not seem reasonable to search for universal mechanisms, but it does seem reasonable to search for evidence of specific, well-defined microbial involvement in corrosion processes. For example, demonstrating the presence of elemental sulfur in the corrosion of mild steel can be considered evidence of SRB corrosion, and demonstrating the presence of manganese oxides in the corrosion of stainless steel can be considered evidence of MOB corrosion. However, even in these examples there is a possibility that some aspects of microbial participation escape our attention. The deposition of manganese oxides is easy to demonstrate on stainless steels or other passive metals because they are stable on such surfaces. However, if MOB deposit manganese oxides on mild steel where the oxides are reduced at the same rate as they are deposited, the corrosion rate may increase without the evidence of microbial participation in the process, the deposits of manganese oxides, being detectable.

Acknowledgments This work was partially supported by the United States Office of Naval Research (contract nos. N00014-99-1-0701 and N00014-06-1-0217). Beyenal was supported by Washington State University (fund no. 9904) and 3M.

\section{References}

Acuna N, Ortega-Morales BO, Valadez-Gonzalez A (2006)Biofilm colonization dynamics and its influence on the corrosion resistance of austenitic UNSS31603 stainless steel exposed to Gulf of Mexico seawater. Mar Biotechnol 8:62-70

Al Darbi MM, Agha K, Islam MR (2005) Comprehensive modelling of the pitting biocorrosion of steel. Can J Chem Eng 83:872-881

Amaya H, Miyuki H (1994) Mechanism of microbially influenced corrosion on stainless-steels in natural seawater. Journal of the Japan Institute of Metals 58:775-781

Antony PJ, Chongdar S, Kumar P, Raman R (2007) Corrosion of 2205 duplex stainless steel in chloride medium containing sulfate-reducing bacteria. Electrochim Acta 52:3985-3994

ASM Handbook Series (1987) Corrosion: Materials. ASM International

Beech IB, Gaylarde CC (1999) Recent advances in the study of biocorrosion - An overview. Rev Microbiol 30:177-190 
ieech IB, Sunner JA, Hiraoka K (2005) Microbe-surface interactions in biofouling and biocorrosion processes. Int Microbiol 8:157-168

ieech WB, Sunner J (2004) Biocorrosion: Towards understanding interactions between biofilms and metals. Curr Opin Biotechnol 15:181-186

olwell R (2006) Understanding royal navy gas turbine sea water lubricating oil cooler failures when caused by microbial induced corrosion ("SRB"). J Eng Gas Turbines Power - Trans ASME 128:153-162

iorenstein SB (1994) microbiologically influenced corrosion handbook. Industrial Press, New York iraughton KR, Lafond RL, Lewandowski Z (2001) The influence of environmental factors on the rate and extent of stainless steel ennoblement mediated by manganese-oxidizing biofilms. Biofouling 17:241-251

'aspi R, Tebo BM, Haygood MG (1998) c-Type cytochromes and manganese oxidation in Pseudomonas putida MnB1. Appl Environ Microbiol 64:3549-3555

'handrasekaran P, Dexter SC (1993) Mechanism of potential ennoblement on passive metals by seawater biofilms (paper no. 493). CORROSION/93, NACE International, Houston, TX

'oetser SE, Cloete TE (2005) Biofouling and biocorrosion in industrial water systems. Crit Rev Microbiol 31:213-232

'ostello JA (1974) Cathodic depolarization by sulfate-reducing bacteria. S Afr J Sci 70:202-204

'rolet JL (1991) From biology and corrosion to biocorrosion. In: Sequeira CAC, Tiller AK (eds.) Proceedings of the 2nd EFC workshop on Microbial Corrosion. HMSO, London, pp 50-60

'rolet JL (1992) From biology and corrosion to biocorrosion. Oceanol Acta 15:87-94

Jexter SC, Gao GY (1988) Effect of seawater biofilms on corrosion potential and oxygen reduction on stainless steels. Corrosion 44:717

Jickinson WH, Lewandowski Z (1996) Manganese biofouling and the corrosion behavior of stainless steel. Biofouling 10:79-93

Jickinson WH, Lewandowski Z (1998) Electrochemical concepts and techniques in the study of stainless steel ennoblement. Biodegradation 9:11-21

Jickinson WH, Caccavo F, Lewandowski Z (1996a) The ennoblement of stainless steel by manganic oxide biofouling. Corros Sci 38:1407-1422

Jickinson WH, Lewandowski Z, Geer RD (1996b) Evidence for surface changes during ennoblement of type $316 \mathrm{~L}$ stainless steel: Dissolved oxidant and capacitance measurements Corrosion 52:910-920

Jickinson WH, Caccavo F, Olesen B, Lewandowski Z (1997) Ennoblement of stainless steel by the manganese-depositing bacterium Leptothrix discophora. Appl Environ Microbiol 63:2502-2506

jashwar M, Maruthamuthu S (1995) Mechanism of biologically produced ennoblement Ecological perspectives and a hypothetical model. Biofouling 8:203-213

inster K, Liesack W, Thamdrup B (1998) Elemental sulfur and thiosulfate disproportionation by Desulfocapsa sulfoexigens sp nov, a new anaerobic bacterium isolated from marine surface sediment. Appl Environ Microbiol 64:119-125

ilemming HC (1995) Biofouling and biocorrosion - Effects of undesired biofilms. Chem Ing Tech 67:1425-1430

ilemming HC, Wingender J (2001) Relevance of microbial extracellular polymeric substances (EPSs) - Part II: Technical aspects. Water Sci Technol 43:9-16

iord T, Mitchell R (1990) The ecology of microbial corrosion. Adv Microb Ecol 11:231-262

irancis CA, Tebo BM (2002) Enzymatic manganese(II) oxidation by metabolically dorman spores of diverse Bacillus species. Appl Environ Microbiol 68:874-880

Jeiser M, Avci R, Lewandowski Z (2002) Microbially initiated pitting on 316L stainless steel. Int Biodeterior Biodegrad 49:235-243

Iakkarainen TJ (2003) Microbiologically influenced corrosion of stainless steels - What is required for pitting? Mater Corros/Werkstoffe Korrosion 54:503-509

familton WA (2003) Microbially influenced corrosion as a model system for the study of metal microbe interactions: A unifying electron transfer hypothesis. Biofouling 19:65-76
Hernandez G, Pedersen A, Thierry D, Hermansson M (1990) Bacterial effects of corrosion of stee in seawater. In: Dowling NJ, Mittelman MW, Danko JC (eds) Proceedings - Microbially influenced corrosion and biodeterioration, University of Tennessee, Knoxville

Hernandez G, Kucera V, Thierry D, Pedersen A, Hermansson M (1994) Corrosion inhibition or steel by bacteria. Corrosion 50:603-608

Herro HM (1991) Tubercle formation and growth on ferrous alloys (paper no. 84). NACE Cincinnati, Ohio

Hossain MA, Das CR (2005) Kinetic and thermodynamic studies of microbial corrosion of milc steel specimen in marine environment. J Indian Chem Soc 82:376-378

Ilhan-Sungur E, Cansever N, Cotuk A (2007) Microbial corrosion of galvanized steel by a freshwater strain of sulphate reducing bacteria (Desulfovibrio sp.). Corros Sci 49:1097-1109

Javaherdashti RA (1999) Review of some characteristics of MIC caused by sulfate-reducing bacteria: Past, present and future. Anti-Corros Methods Mater 46:173-180

Jayaraman A, Ornek D, Duarte DA, Lee CC, Mansfeld FB, Wood TK (1999) Axenic aerobic biofilms inhibit corrosion of copper and aluminum. Appl Microbiol Biotechnol 52:787-790

Lee AK, Newman DK (2003) Microbial iron respiration: Impacts on corrosion processes. App Microbiol Biotechnol 62:134-139

Lee W, Lewandowski Z, Nielsen PH, Hamilton WA (1995) Role of sulfate-reducing bacteria ir corrosion of mild-steel - A review. Biofouling 8:165-194

Lewandowski Z, Beyenal H (2007) Fundamentals of biofilm research. CRC

Lewandowski Z, Dickinson W, Lee W (1997) Electrochemical interactions of biofilms with meta surfaces. Water Sci Technol 36:295-302

Lewandowski Z, Beyenal H, Stookey D (2004) Reproducibility of biofilm processes and th meaning of steady state in biofilm reactors. Water Sci Technol 49:359-364

Linhardt P (1996) Failure of chromium-nickel steel in a hydroelectric power plant by manganese oxidizing bacteria. In: Heitz E, Flemming HC, Sand W (eds.) Microbially influenced corro sion of materials. Springer Verlag, Berlin Heidelberg, pp 221-230

Linhardt P (1998) Electrochemical identification of higher oxides of manganese in corrosion relevant deposits formed by microorganisms. Electrochemical Methods in Corrosion Researcl VI, Pts 1 \& 2. Book Series: Materials Science Forum, Vol. 289-2:1267-1274

Linhardt P (2004) Microbially influenced corrosion of stainless steel by manganese oxidizins microorganisms. Mater Corros/Werkstoffe Korrosion 55:158-163

Linhardt P (2006) MIC of stainless steel in freshwater and the cathodic behaviour of biomineral ized Mn-oxides. Electrochim Acta 51:6081-6084

Little B, Ray R (2002) A perspective on corrosion inhibition by biofilms. Corrosion 58:424-428

Little B, Lee J, Ray R (2007) A review of 'green' strategies to prevent or mitigate microbiologi cally influenced corrosion. Biofouling 23:87-97

Little BJ, Ray RI, Pope RK (2000) Relationship between corrosion and the biological sulfur cycle A review. Corrosion 56:433-443

rew of electrochemical techniques applied to microbio logically influenced corrosion. Corros Sci 32:247-272

(1997) Biofilm development durin nnoblement of stainless steel in Baltic Sea water: A microscopic study. Int Biodeterio Biodegrad 40:1-10

Miyanaga K, Terashi R, Kawai H, Unno H, Tanji Y (2007) Biocidal effect of cathodic pro ection on bacterial viability in biofilm attached to carbon steel. Biotechnol Bioeng 97 $850-857$

Mollica A, Trevis A (1976) Correlation entre la formation de la pellicule primaire et la modifica tion de le cathodique sur des aciers inoxydables experimentes en eau de mer aux vitesses $d$ $0.3 \mathrm{~A}, 5.2 \mathrm{~m} / \mathrm{s}$. Proceedings of 4 th international congress on marine corrosion and fouling Juan Les-Pins, France, 14-18 June 1976

Nielsen P, Lee WC, Morrison M, Characklis WG (1993) Corrosion of mild steel in an alternatin oxic and anoxic biofilm system. Biofouling 7:267-284 
lesen BH, Avci R, Lewandowski Z (2000a) Manganese dioxide as a potential cathodic reactant in corrosion of stainless steels. Corros Sci 42:211-227

lesen BH, Nielsen PH, Lewandowski Z (2000b) Effect of biomineralized manganese on the corrosion behavior of C1008 mild steel. Corrosion 56:80-89

lesen BH, Yurt N, Lewandowski Z (2001) Effect of biomineralized manganese on pitting corrosion of type 304L stainless steel. Mater Corros/Werkstoffe Korrosion 52:827-832

ao TS, Sairam TN, Viswanathan B, Nair KVK (2000) Carbon steel corrosion by iron oxidising and sulphate reducing bacteria in a freshwater cooling system. Corros Sci 42:1417-1431

oe FL, Lewandowski Z, Funk T (1996) Simulating microbiologically influenced corrosion by depositing extracellular biopolymers on mild steel surfaces. Corrosion 52:744-752

omero JM, Angeles-Chavez C, Amaya M (2004) Role of anaerobic and aerobic bacteria in localised corrosion: Field and laboratory morphological study. Corros Eng Sci Technol 39:261-264

chmitt G (1991) Effect of elemental sulfur on corrosion in sour gas systems. Corrosion 47:285-308

edriks AJ (1996) Corrosion of stainless steel. Wiley, New York

hi X, Avci R, Lewandowski Z (2002a) Microbially deposited manganese and iron oxides on passive metals - Their chemistry and consequences for material performance. Corrosion 58:728-738

hi XM, Avci R, Lewandowski Z (2002b) Electrochemistry of passive metals modified by manganese oxides deposited by Leptothrix discophora: Two-step model verified by ToF-SIMS Corros Sci 44:1027-1045

tarosvetsky J, Starosvetsky D, Armon R (2007) Identification of microbiologically influenced corrosion (MIC) in industrial equipment failures. Eng Fail Anal 14:1500-1511

ebo BM, Ghiorse WC, van Waasbergen LG, Siering PL, Caspi R (1997) Bacterially mediated mineral formation: Insights into manganese(II) oxidation from molecular genetic and biochemical studies. Geomicrobiology: Interactions between Microbes and Minerals. Book Series: Reviews in Mineralogy, 35:225-266

ebo BM, Bargar JR, Clement BG, Dick GJ, Murray KJ, Parker D, Verity R, Webb SM (2004) Biogenic manganese oxides: Properties and mechanisms of formation. Annu Rev Earth Planet Sci 32:287-328

ebo BM, Johnson HA, McCarthy JK, Templeton AS (2005) Geomicrobiology of manganese(II) oxidation. Trend Microbiol 13:421-428

Fidela HA (2001) Microbially induced corrosion: An updated overview (reprinted). Int Biodeterior Biodegrad 48:176-201

Videla HA, Herrera LK (2005) Microbiologically influenced corrosion: Looking to the future. Int Microbiol 8:169-180

Nang W, Wang J, Xu H, Li X (2006) Some multidisciplinary techniques used in MIC studies. Mater Corros/Werkstoffe Korrosion 57:531-537

Nashizu N, Katada Y, Kodama T (2004) Role of H2O2 in microbially influenced ennoblement of open circuit potentials for type 316L stainless steel in seawater. Corros Sci 46:1291-1300

White DC, de Nivens PD, Nichols J, Mikell AT, Kerger BD, Henson JM, Geesey G, Clarke CK (1985) Role of aerobic bacteria and their extracellular polymers in facilitation of corrosion: Use of Fourier transforming infrared spectroscopy and "signature" phospholipid fatty acid analysis. In: Dexter SC (ed.) Biologically induced corrosion. NACE, Houston, p 233

Xu CM, Zhang YH, Cheng GX, Zhu WS (2007) Localized corrosion behavior of 316L stainless steel in the presence of sulfate-reducing and iron-oxidizing bacteria. Mater Sci Eng A Struct Mater: Properties Microstruct Process 443:235-241

Zuo RJ, Kus E, Mansfeld F, Wood TK (2005) The importance of live biofilms in corrosion protec tion. Corros Sci 47:279-287

\section{Industrial Biofilms and their Control}

\section{P. Sriyutha Murthy (四) and R. Venkatesan}

Abstract Biofilms are considered to be ubiquitous in industrial and drinking water distribution systems. Biofilms are a major source of contribution to biofouling in industrial water systems. The problem has wide ranging effects, causing damage to materials, production losses and affecting the quality of the product. The problem of biofouling is operationally defined as biofilm development that exceeds a given threshold of interference. It is for the plant operators to keep biofilm developmen below the threshold of interference for effective production and to work out values for threshold limits for each of the technical systems. Industrial biofilms are quite diverse and knowledge gained with a certain type of biofilm may not be applicable to others In recognition of this, the old concept of a universal/effective biocide is a misnomer as physical, chemical and biological parameters of source water vary from site to site and so do the interactions of biocides with these parameters. Control methods have to be tailor-made for a given technical system and cannot be extrapolated. Because of the wide-ranging complexity in industrial technical systems, understanding the biofilm processes, detection, monitoring, control and management is imperative for efficien plant operation. A successful antifouling strategy involves prevention (disinfecting regularly, not allowing a biofilm to develop beyond a given threshold), killing of organisms and cleaning of surfaces. Killing of organisms does not essentially imply cleaning as most industrial systems deploy only biocides for killing, and the cleaning process is not achieved. Cleaning is essential as dead biomass on surfaces provide a suitable surface and nutrient source for subsequent attachment of organisms. A firs step in a biofilm control programme is detection and assessment of various biofilm components, like thickness of slime layer, algal and bacterial species involved, exten of extracellular polymeric substances and inorganic components. Prior to adopting a biocidal dose and regime in an industrial system, laboratory testing of biocides using side-stream monitoring devices, under dynamic conditions, should be carried out to check their effectiveness. Online monitoring strategies should be adopted and biocida

P.S. Murthy

Biofouling and Biofilm Processes Section, Water and Steam Chemistry Division, BARC Facilities Indira Gandhi Center for Atomic Research Campus Kalpakkam, 603 102, India e-mails: psm_murthy@yahoo.co.in, psmurthy@igcar.gov.in 